\title{
Using Cognitive Work Analysis to Inform Policy Recommendations to Support Fuel-Efficient Driving
}

\author{
Craig K. Allison and Neville A. Stanton \\ Faculty of Engineering and the Environment, University of Southampton, Boldrewood \\ Innovation Campus, Southampton, SO16 7QF, United Kingdom \\ \{Craig.Allison, N.Stanton\}@soton.ac.uk
}

\begin{abstract}
The role of man-made emissions in climate change has been a large focus of academic research and political discussion. One considerable source of emissions is everyday driving, and finding ways to reduce driving emissions is a great challenge. This paper presents the use of Cognitive Work Analysis as a potential tool in helping address this problem. Focusing on Control Task Analysis and Social Organization and Cooperation Analysis, this paper discusses the indirect role governmental organizations can play in reducing driving-related emissions. It is proposed that the use of Cognitive Work Analysis can provide insights not typically garnered from traditional academic literature surrounding eco-driving, including the role governmental organizations can play in reducing everyday emissions.
\end{abstract}

Keywords: Human Factors · Cognitive Work Analysis · Eco-Driving

\section{Introduction}

The Earth's average temperature has risen by approximately $0.6^{\circ} \mathrm{C}$ since the start of the twentieth century [1]. Although this change may sound small, it is in fact a greater increase than seen across the entirety of the preceding millennium [2]. Furthermore, these changes are not universal, but rather are spatially heterogeneous [1], with regions of high human population density and industrial activity experiencing the greatest increase of mean temperature, in some cases greater than $1^{\circ} \mathrm{C}$. These population centers, typically Europe, North America and Asia, are primarily developed nations, with developed economies, industrial centers and national infrastructure. Interestingly these regions have also seen an increase in rainfall over the past century with some seeing as much as a $20 \%$ increase in precipitation, whilst less industrially focused regions, such as Africa, Latin America and the Mediterranean, have seen a drop in precipitation equal to approximately $20 \%$ [1]. Based on these trends it is difficult to suggest that human activity is not impacting our environment, and influencing both climate and weather. Indeed, the scientific community has been increasingly vocal in drawing links between man-made emissions and climate change [3]. Whilst the longterm impact of climate change is still unknown, and indeed the impact of our current emission rates still developing, an increase of temperature beyond $2{ }^{\circ} \mathrm{C}$ has become globally accepted as the final opportunity for risk mitigation [4]. The prime approach 
in tackling climate change is reducing greenhouse gas emissions, including Carbon Dioxide $\left(\mathrm{CO}_{2}\right)$ and Nitrogen Oxides (NOx).

One significant contributor to greenhouse emissions is transportation. Within the European Union (EU), transportation is responsible for approximately $25 \%$ of greenhouse gas emissions, the second highest after electricity generation [5]. Road transportation, typically personal cars, is the main contributor to this statistic, accounting for approximately $75 \%$ of transport greenhouse gas emissions [5]. These emissions trends are not limited to the EU, with similar trends being seen in the United States of America, whereby car use accounts for between $32 \%$ and $41 \%$ of total $\mathrm{CO}_{2}$ emissions [6][7]. As a by-product of internal combustion, $\mathrm{CO}_{2}$ is the main gas released from car exhausts, and whilst an essential atmospheric element, is a greenhouse gas contributing to global warming and climate change [8]. The impact of $\mathrm{CO}_{2}$ in terms of damages caused as a consequence of climate change can be considered as a financial metric, in what has become known as the "Social Cost of Carbon". This figure states the value of damages avoided by saving one metric tonne of $\mathrm{CO}_{2}$. Estimates of this cost however vary greatly, between \$21 [9] and \$220 [10] per metric tonne. In addition to $\mathrm{CO}_{2}$, NOx gases are also released during the combustion of fossil fuels. Nitric oxide (NO) is the main NOx emission from most combustion processes and although concentrations of this gas are low, it is highly poisonous. Nitrogen dioxide $\left(\mathrm{NO}_{2}\right)$ is a powerful oxidant and limited quantities are produced during combustion. Nitrous oxide $\left(\mathrm{N}_{2} \mathrm{O}\right)$ whilst not poisonous, is a significant contributor to the greenhouse effect. In addition to the negative impact vehicle emissions have on the environment, they also have a negative impact on human health and wellbeing, with exposure to such emissions leading to an increase risk of developing asthma, bronchitis, chronic obstructive pulmonary disease, pneumonia and upper respiratory tract infection [11].

Vehicle emissions also contain numerous other toxic elements, including unburned hydrocarbons (UHCs), long term exposure to which is known to be carcinogenic [12], carbon monoxide $(\mathrm{CO})$, which is poisonous and potentially fatal in large concentrations [13], and soot, fine particulates of carbon, which can cause respiratory problems and act as a substrate for atmospheric chemical reactions [14].

\subsection{Eco-Driving}

As can be seen, vehicle emissions have a negative impact on both the environment [8][14] and human wellbeing [11][12][13] and steps are required to reduce such emissions. Whilst the development of more fuel-efficient and environmentally friendly vehicle drivetrains can be seen as a priority [15], this development and widespread use will take a significant length of time. An approach to reduce car-based emissions popular within the academic literature is modifying driver behaviors, to promote fuelefficient driving techniques referred to as eco-driving [16]. Eco-driving is characterized by behaviors such as modest acceleration, gentle braking, driving at lower speeds, limiting idling, early gear changes and limiting the engine to approximately 2,500 revolutions per minute (RPM). By engaging with eco-driving, drivers can save approximately $5 \%-20 \%$ of fuel, subsequently reducing the associated emissions, in particular, $\mathrm{CO}_{2}$ emissions, since these are directly proportional to the fuel used. Indeed, specific eco-driving training has been demonstrated to reduce fuel usage in a variety of both simulator and on-road studies by an average of $9 \%$ [17]. Despite the 
proposed benefits of eco-driving, research has suggested that drivers struggle to maintain eco-driving long term. Within one such study, exploring the fuel use of bus drivers, it was found that despite the initial success of an eco-driving training course demonstrated by a $10.2 \%$ reduction in fuel use, this figure had dropped to a $4.35 \%$ saving just two months after the course [18]. Based on this and similar research [19], it is clear that drivers require additional support to maintain long-term fuel savings.

\subsection{Cognitive Work Analysis}

One tool that that may be of significant value in supporting the long-term adoption of eco-driving behaviors is Cognitive Work Analysis (CWA). CWA is a framework for understanding complex socio-technical systems, characterized by close interactions of people and technology [20]. CWA aims to understand the constraints that surround different systems, seeking to understand the requirements, possibilities and potential of the system under examination. By focusing on constraints, CWA seeks to understand and support worker needs for improved efficiency and safety [21]. CWA has been used to facilitate understanding of a variety of complex systems, including military planning systems [22], team design [23], aviation [24] and driving [25].

The complete CWA process comprises five key phases, each of which is designed to build on insight gained from previously completed phases. The first phase, and most commonly completed [26], aspect of CWA is the Work Domain Analysis (WDA), which is commonly presented within an abstraction hierarchy, mapping the proposed system on multiple conceptual levels, ranging from its overall purpose to the physical objects that it is comprised of [27]. The second phase, the Control Task Analysis, examines the constraints that operate on a system within set conditions, defining the available inputs and end goal of the system [28] via the use of the contextual activity template. The third phase is the Strategies Analysis (StrA) [28] that explores the different strategies that individuals can use to achieve set end goals within the system. This phase is typically presented within flow maps, defining start and end states of the system and describing the steps users are required to complete in order to transform the system from the start to the desired end state [28] [29]. The fourth phase of CWA, Social Organization and Cooperation Analysis (SOCA), examines the allocation of tasks within the system, accounting equally for both human and technological agents [30]. SOCA maps the responsibility of given tasks to different agents and offers an opportunity to reallocate tasks to improve efficiency and safety. Whilst there is no clearly established dedicated methodology for this step [30], SOCA is typically completed by annotating previous outputs of the CWA process, including the abstraction hierarchy completed within phase 1 and the contextual activity template completed within phase 2. The final phase of the CWA framework is the Worker Competency Analysis, focusing on psychological constraints of the users of systems [31]. Worker Competency Analysis often draws upon the Skills, Rules and Knowledge taxonomy (SRK taxonomy) to map out the level of cognitive effort applied to the different tasks. Although a complete CWA analysis is a considerable investment in time and work, the insights it can offer can be used to justify the required investment. Despite a complete CWA being completed for the current project, focus here will be given to phases 
2 and 4, the Control Task Analysis and Social Organization and Cooperation Analysis phases, and explore the insights that these two phases can offer practitioners.

\section{$2 \quad$ Method}

To create a complete CWA for eco-driving, a workshop session was run focusing on the initial development of the CWA. Nine participants, aged $27-57$ years old $(M=$ 36.33, S.D. = 10.84) attended the session. Workshop attendees had an extensive knowledge of car and drivetrain mechanics, traffic modeling, eco-driving, Human Factors and fuel usage. The workshop guided participants through the theoretical underpinnings of the CWA process, completing a detailed abstraction hierarchy as well as laying the foundations for the remaining CWA stages.

Following the workshop, the research team continued to elaborate and hone the CWA, seeking validation from the session's attendees once each of the five phases had been fully completed. Feedback from the session attendees was used to refine the developed CWA to ensure that it accurately reflected participants' opinions and the content of the workshop. Where disagreements arose, the group was required to make a collective decision in order to ensure that the completed CWA accurately represented the whole groups' knowledge.

\section{Results and Discussion}

Whilst all stages of CWA can offer significant insight into idea development, focus is given here to the Control Task Analysis (Phase 2) and Social Organization and Cooperation Analysis (Phase 4). It has been proposed [32] that an ideal tool for Control Task Analysis is the Contextual Activity Template (CAT). Within this framework, all Object Related Processes identified within the abstraction hierarchy are considered across multiple potential situations. Situations can be be as a consequence of spatial constraints, for example driving on a specific road type or temporal constraints such as a consequence of a time sensitive task, for example waiting at traffic lights. The primary objective of a CAT analysis is to identify when and under what conditions a task is completed. To map this analysis, a matrix was developed whereby the object related processes identified within the abstraction hierarchy was plotted against a variety of different road types and road situations that a driver could be faced. The matrix was then overlaid with box and whisker plots to map the likelihood of each Object Related Process taking place within the situation. A box within a cell represents that the task can be completed within the situation; a circle or whisker indicating that the activity can be performed within the current situation and typically is and a cell with no markings indicates that an activity is not possible with the situation. For the current analysis, all 39 Object Related Processes, identified within the abstraction hierarchy generated in phase one, were considered in a variety of different road situations. In total 23 different situations were considered: Motorway Clear, Motorway Congested, Urban, Major A-road, Country Road, Junction, Rural, Residential, Planning Journey, In-car Pre engine start, Waiting at Traffic Lights, Waiting at a Junction, 
On a Slip Road, Post Journey, Engine Turned off, Pre Journey, Engine Started, Handbrake on, On a Roundabout, Initial Acceleration from Stationary, Cruising/ Steady Speed, Overtaking, Parking, Emergency Stopping, Reversing, and General Braking. Figure 1 presents a section of the created CAT analysis. As can be seen the majority of Object Related Processes are common to all situations, with limited differences based on the considered situation.

\begin{tabular}{|c|c|c|c|c|c|c|c|c|c|c|c|c|c|c|}
\hline Situations & Motonway Clear & $\begin{array}{l}\text { Motonoway } \\
\text { Congested }\end{array}$ & Urban & Major A-road & Country Road & Junction & Rural & Residential & Planning Journey & $\begin{array}{l}\text { In Car- Pre } \\
\text { engine start }\end{array}$ & $\begin{array}{l}\text { Waiting at Traftic } \\
\text { Lights }\end{array}$ & $\begin{array}{l}\text { Waiting at a } \\
\text { Junction }\end{array}$ & On Slip Road & $\underbrace{}_{\begin{array}{c}\text { Post Je } \\
\text { Engine }\end{array}}$ \\
\hline \multirow{2}{*}{\multicolumn{15}{|c|}{$\begin{array}{l}\text { Display Vehicle } \\
\text { Speed }\end{array}$}} \\
\hline & & & & & & & & & & & & & & \\
\hline \multirow{2}{*}{\multicolumn{14}{|c|}{$\begin{array}{l}\text { Display Vethicle } \\
\text { RPM }\end{array}$}} & \\
\hline & & & & & & -..-. & & & & & $1-\ldots$ & & & \\
\hline \multicolumn{15}{|l|}{ Alert of Hazards } \\
\hline & 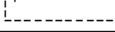 & ---------_- & 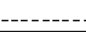 & $-\ldots$ & $\cdots$ & - & -- & 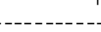 & & & & & & \\
\hline \multirow{2}{*}{\multicolumn{15}{|c|}{$\begin{array}{c}\text { Detecting Traffic } \\
\text { Jams }\end{array}$}} \\
\hline & I'-- & - - & 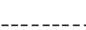 & 年 & & -1--.-- & & - & & & - & & -... & \\
\hline $\begin{array}{c}\text { Provide } \\
\text { Information on }\end{array}$ & 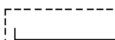 & 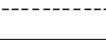 & & & & $\cdots$ & & . & & & & & & \\
\hline $\begin{array}{l}\text { Other Vehicle } \\
\text { Behaviours }\end{array}$ & ! & --- - - & - & .... & & ------ & -- & - & & & 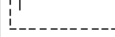 & & $\ldots--$ & \\
\hline Most Fuel Efticien & it & & & & & & & & & & & & & \\
\hline$<$ Path & & & & & & & & & & & & & & $>$ \\
\hline
\end{tabular}

Fig. 1. Excerpt of the completed CAT analysis, as can be seen, the functions are largely consistent across different situations.

Progressing the CWA analysis, and specifically the completed CAT analysis, SOCA seeks to identify the agents that can control and influence a situation [33]. For the current CWA, nine agents were identified as influencing fuel efficient driving; "Driver", "On-Board Computers", "On-Board Displays", "On-Board Sensors", "Other Road Users", "Vehicle Mechanical Systems", "Vehicle Electrical Systems", "The Law" and "Infrastructure Network". Figure 2 presents the SOCA annotation applied to the CAT analysis previously developed, alongside a key presented within Figure 3, highlighting the variety of agents who can influence the fuel efficiency of the vehicle. Of central interest to the current paper is the role played by the "The Law" and "Infrastructure Network". Eco-driving is typically considered from the perspective of behaviors the driver engages with [16], ideas related to overall vehicle efficiency [34] and specific drivetrains [35], but the role that governmental organizations can play is rarely highlighted within scientific literature. 


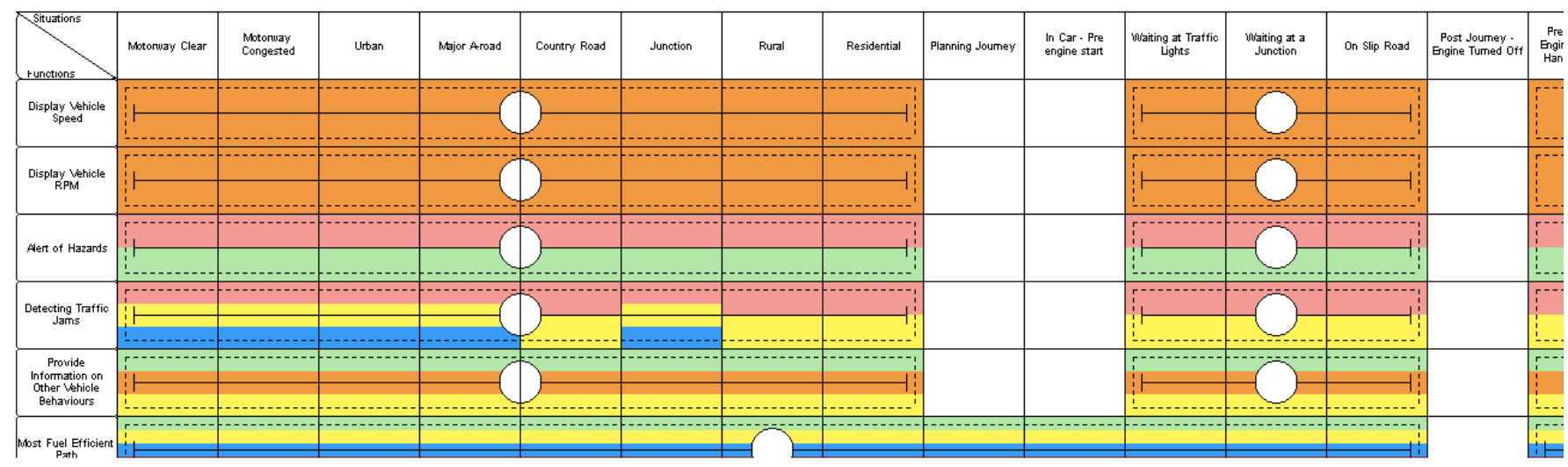

Fig. 2. Excerpt of the completed SOCA-CAT Analysis. It can be seen that multiple agents can influence different considered situations, potentially simultaneously.

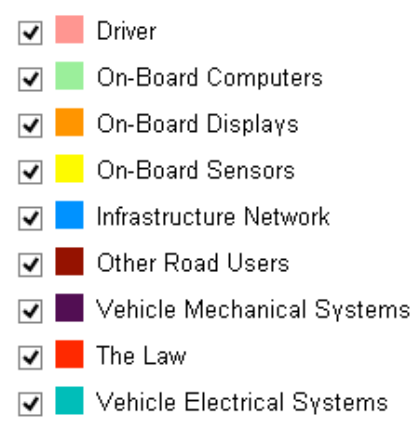

Fig 3. Key to the generated SOCA-CAT analysis, highlighting the identified agents that can influence fuel-efficient driving.

\subsection{Infrastructure Network}

It was found within the SOCA-CAT analysis that "Infrastructure Network" contributed to 11 out of the 39 identified Object Related Processes, "Detecting Traffic Jams", "Most Fuel Efficient Path", "Shortest Path", "Fastest Path", "Traffic Lights", "Road Gradient", "Road Width", "Road Curvature", "Road Adherence", "Speed Limit" and "Smooth Motion". These identified Object Related Processes suggest that governmental investment into infrastructure development can help support greater fuel efficiency. As an example, if infrastructure developments involved the creation alternative routes, such as the development of city ring-roads and bypasses, drivers may gain access to new fastest paths, shorter paths and more fuel efficient paths. In addition, developing infrastructure in this way could further improve fuel efficiency by assisting traffic flow, minimizing required braking and limiting wasted energy. If drivers are required to brake less often, less energy is lost, both during the braking process, and subsequent required acceleration. In addition to direct infrastructure development, investment into road maintenance can assist drivers in achieving greater fuel efficiency, promoting smooth motion, and providing drivers an appropriate road surfaces on which to drive. It should be noted that a key benefit of this approach to fuel-efficient driving is that all these savings are gained without drivers being required to intentionally engage in specific eco-driving behaviors. Although governmental projects related to infrastructure development are significant investments of public funds, such pro- 
jects can offer fuel efficiency savings to drivers, and provide an indirect route to emission reductions.

\subsection{Legislation}

Within the SOCA-CAT analysis it was seen that "The Law" was related to four Object Related Processes, "Speed Limit", "Fastest Path", "Shortest Path" and "Most Fuel Efficient Path". By the nature of the road network drivers are compelled to follow legally prescribed routes, which may not be the shortest geographical paths possible within the network were the driver walking or using alternative forms of transportation such as public bus services. As an example, due to increasing pedestrianisation of city centers, which limits traditional journey routes [36], drivers may be required to follow extensive one way systems, which may at times lead drivers away from their destination. It should be noted however that shortest paths may not be equivalent to most fuel efficient paths. Typical shortest routes within urban environments in particular are typically characterized by increased volume of traffic and start stopping behaviors, increasing fuel consumption.

It can be argued however, that the most visible role of legislation influencing driver's fuel economy is the implementation, and potential of enforcement of, speed limits. It has been documented [16] that traveling below the speed limit is associated with significant reductions in fuel usage and emissions. It can be argued therefore that the government has the potential to reduce speed limits in an effort to reach emission targets. Although such a step could potentially prove unpopular with many road users, reduced speed limits to tackle congestion is an increasingly common trend [37]. Increasingly common across the European Union, variable speed limits are seeing increased deployment across many key motorways (highways) [37]. Increasing adoption of variable speed limits has the potential to reduce emissions, by improving traffic flow, reducing unnecessary idling, acceleration and braking. Reducing speed on high-speed roads such as motorways (highways) can also save fuel as aerodynamic drag forces are greatly reduced at lower speeds [38]. Aerodynamic drag is a significant source of fuel consumption at high speed, with approximately $51 \%$ of propulsive energy being used to overcome aerodynamic drag. This translates to $46 \%$ of the total fuel usage when accounting for braking and idling [39]. This change can offer significant fuel savings when applied to high speed driving, such as for motorway (highway) journeys, whereby slowing from $70 \mathrm{mph}$ to $60 \mathrm{mph}$ would reduce fuel use by approximately $12 \%$. This saving is greater still were speed reduced from $70 \mathrm{mph}$ to $50 \mathrm{mph}$, whereby fuel consumption would be reduced by approximately $23 \%$.

\subsection{Benefits of Cognitive Work Analysis}

As demonstrated the use of CWA has provided numerous insights into fuel-efficient driving, including insights typically not garnered within the academic literature relating to eco-driving practices. By highlighting the role that both the infrastructure network and the law can have on fuel efficient driving in terms of overall fuel use and emissions, the role that governmental organizations can have on everyday emissions has been highlighted. Such insights can be taken forward to provide information that 
can be used as a tool to influence national policy related to emission reduction and as a tool to lobby governmental organizations to develop inclusive strategies to tackle climate change.

A prime benefit of changes enforced at national level is that drivers are not forced to change their driving style, rather drivers are simply required to follow new laws and adapt to changes of speed limits, providing a relatively enforceable approach to emission reduction. As has been seen the potential benefits of variable speed limits, including increased traffic flow and safety [37], can be expanded to also include reduced emissions and fuel use. Although the potential increase in travel time may prove unpopular with drivers, direct financial benefits and cheaper journeys could salve these misgivings long term.

\section{Conclusions}

This paper has presented an abridged account of a CWA developed to support fuelefficient driving, with a focus on the Control Task Analysis and Social Organization and Cooperation Analysis phases of the CWA process. From these phases, in addition to the roles typically considered within fuel efficiency such as driver's behaviors and vehicle mechanical systems, the role that the government plays in fuel efficiency was highlighted. It is proposed that governmental organizations can take a greater role to improve everyday fuel efficiency, leading to valuable legal changes, including the adoption of variable speed limits and greater investment into road infrastructure, which can lead to a significant reduction in driving related greenhouse gas emissions.

Acknowledgments. This work was funded by the UK Engineering and Physical Sciences Research Council (EPSRC) grant EP/N022262/1 "Green Adaptive Control for Future Interconnected Vehicles" (www.g-active.uk). The authors would like to offer thanks to all participants who gave their time to participate within the workshops presented within the current work. The authors would also like to thank the wider GACTIVE project team for their valuable feedback in improving earlier versions of the manuscript.

\section{References}

1. Walther, G. R., Post, E., Convey, P., Menzel, A., Parmesan, C., Beebee, T. J., ... \& Bairlein, F. Ecological responses to recent climate change. Nature, 416(6879), 389 (2002).

2. Third Assessment Report of the Intergovernmental Panel on Climate Change IPCC (WG I \& II) Cambridge Univ. Press, Cambridge (2001).

3. Thornton, J., \& Covington, H. Climate change before the court. Nature Geoscience. (2015). 
4. Meinshausen, M., Meinshausen, N., Hare, W., Raper, S. C., Frieler, K., Knutti, R., ... \& Allen, M. R. Greenhouse-gas emission targets for limiting global warming to 2 C. Nature, 458 (7242), 1158 (2009).

5. Hill, N., Brannigan, C., Smokers, R., Schroten, A., van Essen, H., \& Skinner, I. eu Transport ghg: Routes to 2050 ii. final project report funded by the European Commission's Directorate-General Climate Action, Brussels (2012).

6. Vandenbergh, M. P., \& Steinemann, A. C. Carbon-Neutral Individual, The. NYUL Rev., 82, 1673 (2007).

7. Bin, S., \& Dowlatabadi, H. Consumer lifestyle approach to US energy use and the related CO 2 emissions. Energy Policy, 33(2), 197-208 (2005).

8. Pearce, D. The role of carbon taxes in adjusting to global warming. The economic journal, 101(407), 938-948 (1991).

9. Interagency Working Group on Social Cost of Carbon (2010). Social Cost of Carbon for Regulatory Impact Analysis Under Executive Order 12866. Washington, DC: U.S. Department of Energy.

http://www1 .eere.energy.gov/buildings/appliance_standards/commercial/pdfs/ smallmotors_tsd/sem_finalrule_appendix15a.pdf.

10. Moore, F. C., \& Diaz, D. B. Temperature impacts on economic growth warrant stringent mitigation policy. Nature Climate Change, 5(2), 127 (2015).

11. Buckeridge, D. L., Glazier, R., Harvey, B. J., Escobar, M., Amrhein, C., \& Frank, J. Effect of motor vehicle emissions on respiratory health in an urban area. Environmental health perspectives, 110(3), 293 (2002).

12. Dickhut, R. M., Canuel, E. A., Gustafson, K. E., Liu, K., Arzayus, K. M., Walker, S. E., ... \& MacDonald, E. H. Automotive sources of carcinogenic polycyclic aromatic hydrocarbons associated with particulate matter in the Chesapeake Bay region. Environmental science \& technology, 34(21), 4635-4640 (2000).

13. Raub, J. A., Mathieu-Nolf, M., Hampson, N. B., \& Thom, S. R. Carbon monoxide poisoning - a public health perspective. Toxicology, 145(1), 1-14 (2000).

14. Rose, D., Wehner, B., Ketzel, M., Engler, C., Voigtländer, J., Tuch, T., \& Wiedensohler, A. Atmospheric number size distributions of soot particles and estimation of emission factors. Atmospheric Chemistry and Physics, 6(4), 1021-1031 (2006).

15. Demirdoven, N.; Deutch, J. Hybrid cars now, fuel cell cars later Science, 305 (5686) 974- 976 (2004).

16. Barkenbus, J. N. Eco-driving: An overlooked climate change initiative. Energy Policy, 38(2), 762-769. (2010).

17. Kurani, K., Sanguinetti, A., \& Park, H. "Actual Results May Vary”: A Behavioral Review of Eco--Driving for Policy Makers. White Paper, National Center for Sustainable Transportation, University of California at Davis, Davis, CA, July. (2015).

18. Zarkadoula, M., Zoidis, G., \& Tritopoulou, E. Training urban bus drivers to promote smart driving: A note on a Greek eco-driving pilot program. Transportation Research Part D: Transport and Environment, 12(6), 449-451 (2007).

19. Wåhlberg, A. E. Long-term effects of training in economical driving: Fuel consumption, accidents, driver acceleration behavior and technical feedback. International Journal of Industrial Ergonomics, 37(4), 333-343 (2007).

20. Stanton, N. A., \& Bessell, K. How a submarine returns to periscope depth: Analysing complex socio-technical systems using Cognitive Work Analysis. Applied Ergonomics, 45(1), 110-125 (2014).

21. Stanton, N. A., McIlroy, R. C., Harvey, C., Blainey, S., Hickford, A., Preston, J. M., \& Ryan, B. Following the cognitive work analysis train of thought: exploring the constraints of modal shift to rail transport. Ergonomics, 56(3), 522-540 (2013). 
22. Jenkins, D. P., Stanton, N. A., Salmon, P. M., Walker, G. H., \& Young, M. S. Using cognitive work analysis to explore activity allocation within military domains. Ergonomics, 51(6), 798-815 (2008).

23. Naikar, N., Pearce, B., Drumm, D., \& Sanderson, P. M. Designing teams for first-ofa-kind, complex systems using the initial phases of cognitive work analysis: Case study. Human Factors: The Journal of the Human Factors and Ergonomics Society, 45(2), 202 - 217 (2003).

24. Stanton, N. A., Harris, D., \& Starr, A. The future flight deck: Modelling dual, single and distributed crewing options. Applied Ergonomics, 53, 331-342 (2016).

25. Birrell, S. A., Young, M. S., Jenkins, D. P., \& Stanton, N. A. Cognitive Work Analysis for safe and efficient driving. Theoretical Issues in Ergonomics Science, 13(4), 430-449 (2012).

26. McIlroy, R. C., \& Stanton, N. A. Ecological interface design two decades on: Whatever happened to the SRK taxonomy?. IEEE Transactions on Human-Machine Systems, 45(2), 145-163 (2015).

27. Naikar, N. Work domain analysis: Concepts, guidelines, and cases. CRC Press (2013).

28. Naikar, N. Beyond interface design: Further applications of cognitive work analysis. International Journal of Industrial Ergonomics, 36(5), 423-438. (2006).

29. Ahlstrom, U. Work domain analysis for air traffic controller weather displays. Journal of Safety Research, 36(2), 159-169. (2005).

30. Vicente, K. J. Cognitive Work Analysis: Towards safe, productive, and healthy computer-based work. Mahweh, NJ: LEA (1999).

31. Kilgore, R., \& St-Cyr, O. The SRK inventory: a tool for structuring and capturing a worker competencies analysis. In Proceedings of the Human Factors and Ergonomics Society Annual Meeting (Vol. 50, No. 3, pp. 506-509). Sage CA: Los Angeles, CA: SAGE Publications (2006).

32. Naikar, N., Moylan, A., \& Pearce, B. Analysing activity in complex systems with cognitive work analysis: concepts, guidelines and case study for control task analysis. Theoretical Issues in Ergonomics Science, 7(4), 371-394 (2006).

33. Houghton, R. J., Baber, C., Stanton, N. A., Jenkins, D. P., \& Revell, K. Combining network analysis with Cognitive Work Analysis: insights into social organisational and cooperation analysis. Ergonomics, 58(3), 434-449 (2015).

34. Sivak, M., \& Schoettle, B. Eco-driving: Strategic, tactical, and operational decisions of the driver that influence vehicle fuel economy. Transport Policy, 22, 96-99 (2012).

35. Chan, C. C. The state of the art of electric, hybrid, and fuel cell vehicles. Proceedings of the IEEE, 95(4), 704-718 (2007).

36. Parkhurst, G. Regulating cars and buses in cities: the case of pedestrianisation in Oxford. Economic Affairs, 23(2), 16-21 (2003).

37. Papageorgiou, M., Kosmatopoulos, E., \& Papamichail, I. Effects of variable speed limits on motorway traffic flow. Transportation Research Record: Journal of the Transportation Research Board, (2047), 37-48 (2008).

38. Gillespie, T. D. Vehicle dynamics. Warren dale (1997).

39. Hucho, W. H., \& Sovran, G. Aerodynamics of road vehicles. Annual review of fluid mechanics, 25(1), 485-537 (1993). 